\title{
Facile and rapid detection of respiratory syncytial virus using metallic nanoparticles
}

\author{
Jesus Valdez ${ }^{1}$, Swapnil Bawage ${ }^{2}$, Idalia Gomez ${ }^{1}$ and Shree Ram Singh ${ }^{2 *}$
}

\begin{abstract}
Background: Respiratory syncytial virus (RSV) causes severe respiratory infection in infants, children and elderly. Currently, there is no effective vaccine or RSV specific drug for the treatment. However, an antiviral drug ribavirin and palivizumab is prescribed along with symptomatic treatment. RSV detection is important to ensure appropriate treatment of children. Most commonly used detection methods for RSV are DFA, ELISA and Real-time PCR which are expensive and time consuming. Newer approach of plasmonic detection techniques like localized surface plasmon resonance (LSPR) spectroscopy using metallic nanomaterials has gained interest recently. The LSPR spectroscopy is simple and easy than the current biophysical detection techniques like surface-enhanced Raman scattering (SERS) and mass-spectroscopy.
\end{abstract}

Results: In this study, we utilized LSPR shifting as an RSV detection method by using an anti-RSV polyclonal antibody conjugated to metallic nanoparticles ( $\mathrm{Cu}, \mathrm{Ag}$ and $\mathrm{Au}$ ). Nanoparticles were synthesized using alginate as a reducing and stabilizing agent. RSV dose and time dependent LSPR shifting was measured for all three metallic nanoparticles (non-functionalized and functionalized). Specificity of the functionalized nanoparticles for RSV was evaluated in the presence Pseudomonas aeruginosa and adenovirus. We found that functionalized copper nanoparticles were efficient in RSV detection. Functionalized copper and silver nanoparticles were specific for RSV, when tested in the presence of adenovirus and $P$. aeruginosa, respectively. Limit of detection and limit of quantification values reveal that functionalized copper nanoparticles are superior in comparison with silver and gold nanoparticles.

Conclusions: The study demonstrates successful application of LSPR for RSV detection, and it provides an easy and inexpensive alternative method for the potential development of LSPR-based detection devices.

Keywords: RSV, Detection, Metallic nanoparticles, LSPR, SERS, Mass spectroscopy, Limit of detection, Limit of quantification, Plasmonics, Sensing

\section{Background}

Nanobiotechnology provides interdisciplinary applications such as detection, sensing, targeting, drug delivery and disease treatments [1-11]. Sensing and detection has been the subject of research in recent years using localized surface plasmon resonance (LSPR), which provides a new and easy method for their applications.

The LSPR are coherent oscillations of conducting electrons on the excited surface of a metal due to the interaction with electromagnetic radiation. These oscillations

\footnotetext{
*Correspondence: ssingh@alasu.edu

${ }^{2}$ Center for NanoBiotechnology Research, Alabama State University, 1627,

Harris way, Montgomery, AL 36104, USA

Full list of author information is available at the end of the article
}

provide an extinction band in the range of infrared, visible and ultraviolet spectra. The spectral position (wavelength) of these phenomena is highly sensitive and particular to the type of metal, size, shape and the surrounding dielectric field [12] and their study is known as "plasmonics" [13-15]. The position in the spectra for the LSPR can be altered depending on the dielectric constant surrounding the metallic nanoparticles. This alteration can be observed as a blue-red shift for the LSPR peak, and it can be a useful mean for sensing applications [16].

Sensing applications involve the use of plasmon which could be enhanced and refined by improving the interactions of the electric field and metallic nanoparticles which are proportional. These improvement could help 
in areas of sensing because of the extraordinary sensitivity to lower concentration of chemicals [17]. Currently, the analytes studied using LSPR are metal ions [18], toxins [19], glucose [20], nucleic acids [21], molecules [22] and antigen/antibodies [23, 24]. Plasmonic nanoparticles have been used for the detection of bacteria and viruses such as Salmonella serovars [25] and HIV-1 [26], respectively. Detection of biological entities of respiratory diseases such as influenza viruses [3,27] have been carried out using nanoparticle-based detection. For RSV detection, some studies reported use of surface-enhanced Raman scattering (SERS) of silver [28] nanoparticles and quantum dots (QDs-CdTe) based UV-visible spectroscopy $[29,30]$.

Respiratory syncytial virus (RSV) is a paramyxovirus that leads to mild, cold-like symptoms in adults and children. However, it can be more serious in infants and elderly people. Globally, RSV infection is estimated at 64 million cases and 160,000 deaths annually [31]. In the USA, the estimated infantile RSV mortality rate was shown to be more than that of influenza [32]. Therefore, early RSV detection and treatment are extremely important. It is commonly seen that RSV infection is associated with other respiratory bacterial and viral pathogens. In addition, the respiratory disease diagnosis may be difficult to differentiate between RSV and other microorganisms. The symptoms are confusing and treatment cannot be certain as the etiological agent is not known, leading to complications. For example, the respiratory infection symptoms for RSV and Adenovirus cannot be distinguishable during the acute phases of the illnesses [33]. RSV is responsible for promoting Pseudomonas aeruginosa infection [34]. In fact, mixed infection is commonly observed during respiratory illness.

The most used and commercialized method for detection of RSV is the direct fluorescence antibody (DFA) that is based on the microscopic detection with an antibody conjugated to a fluorophore. ELISA is another widely used hospital diagnostic assays for RSV detection. Realtime PCR is used to amplify and simultaneously detect or quantify a targeted DNA molecule. It is highly sensitive with very low limits of detection but it is an expensive method [35].

The biophysical methods, like PCR coupled with electrospray ionization mass spectrometry (PCR-ESI-MS) and SERS are used for RSV detection but it is largely limited for research purpose. PCR-ESI-MS is a highly sensitive and specific method even at strain level, not only for RSV but also for multiple pathogens detections [36, 37]; however, it is an expensive procedure. On the other hand, SERS is a rapid and nondestructive detection method with high sensitivity $[38,39]$, but the disadvantages are costs and sample preparations. However, the advantages of SERS can be availed by using LSPR spectroscopy, which serves an alternative biophysical technique to detect RSV. In this study it is showed the LSPR application of antibody-functionalized copper, silver and gold nanoparticles for the RSV detection and screened their cross-reactivity under the influence of other respiratory pathogens.

\section{Results}

\section{Nanoparticles synthesis and UV-visible characterization}

Metallic nanoparticles were synthesized by reducing and stabilizing them with alginate assisted by microware radiation. The dry weight for $200 \mu \mathrm{L}$ of copper, silver and gold nanoparticles were $16.9 \pm 0.39,15.7 \pm 0.17$ and $8.3 \pm 0.3 \mathrm{mg}$, respectively. The characteristic plasmonic absorption of copper, silver and gold nanoparticles was 620, 400 and $530 \mathrm{~nm}$, respectively (Fig. 1).

\section{Functionalization of nanoparticles for optimum LSPR}

All three nanoparticles were functionalized with three different volumes $(2.5,5$ and $10 \mu \mathrm{L})$ of polyclonal antibody $(4 \mathrm{mg} / \mathrm{mL})$ for screening optimal LSPR that could be used for RSV detection. Generally, functionalization of nanoparticles reduces LSPR signal, however functionalization of nanoparticles with antibody increase the RSV detection. Therefore, fNP were appropriately selected to balance, both these desired qualities. The functionalization process was optimized at $5 \mu \mathrm{L}(20 \mu \mathrm{g})$ of antibody for copper and gold nanoparticles and $10 \mu \mathrm{L}(40 \mu \mathrm{g})$ for silver nanoparticles (Fig. 1). Henceforth, the nanoparticles were functionalized with these antibody concentrations for RSV detection.

\section{Particle size distribution and zeta potential}

The particle size distribution for the non-functionalized (NP) and fNP is shown in Fig. 2. Particle size distribution (Fig. 2a) for copper nanoparticles was $254 \pm 11.11 \mathrm{~nm}$. For silver and gold nanoparticles (Fig. 2d, e) there was a similar distribution with one peak in $10-20 \mathrm{~nm}$ and another one in $151 \pm 0.57$ and $185 \pm 4.37 \mathrm{~nm}$, respectively. Functionalized nanoparticles (Fig. 2b, e, g) were larger in size than NP nanoparticles. For copper and silver nanoparticles, sizes increased up to130 nm approximately, and for gold nanoparticles, two peaks of $118 \pm 2.82$ and $585 \pm 52 \mathrm{~nm}$ were observed.

The zeta potential for copper nanoparticles was $-17.2 \mathrm{mV}$, and upon functionalization the potential changed to $10 \mathrm{mV}$. Silver and gold nanoparticles showed a potential of -37 and $-40 \mathrm{mV}$ respectively, and after functionalization they had potentials of $-18 \mathrm{mV}$ for silver and $-20 \mathrm{mV}$ for gold (Fig. 3). 

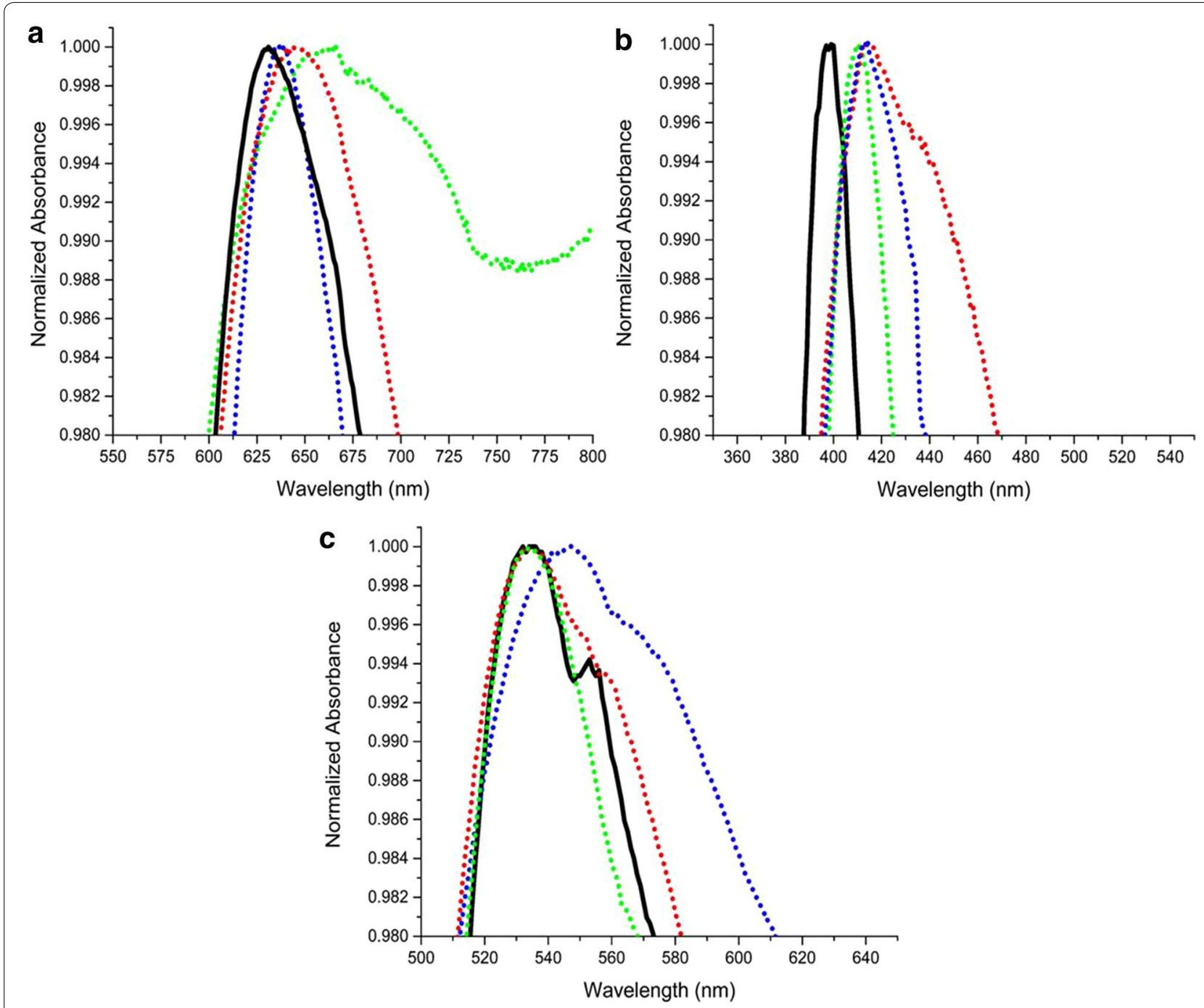

$\square$ NP $\square$ fNP-2.5 $\mu$ LAb $\square$ fNP-5 $\mu$ LAb $\square$ fNP-10 $\mu$ LAb

Fig. 1 UV-visible analyses for the synthesized nanoparticles using alginate (black line) and their respective antibody functionalization using 2.5 (red), 5 (blue) and $10 \mu \mathrm{L}$ (green) with polyclonal antibody at $3 \mathrm{~h}$ for copper (a), silver (b) and gold (c) nanoparticles

\section{Determination of antibody functionalized on the nanoparticles}

The supernatant and washes from the antibody fNP were subjected to protein estimation using the BCA (ThermoScientific, NY, USA). The antibody attached to the surface of nanoparticles was $18.56 \pm 0.38 \mu \mathrm{g}$ of $20 \mu \mathrm{g}$ (93.3\%) for copper, 33. $60 \pm 0.49 \mu \mathrm{g}$ of $40 \mu \mathrm{g}(84 \%)$ for silver and $11.04 \pm 1.6 \mu \mathrm{g}$ of $20 \mu \mathrm{g}(55.2 \%)$ for gold.

\section{Field emission-scanning electron microscopy}

FE-SEM micrographs for NP indicate the size of all NPs to be less than $100 \mathrm{~nm}$ with few visible agglomerations (Fig. 4).

\section{RSV detection}

The magnitude of interaction between the RSV and functionalized nanoparticle is reflected as a corresponding measurable LSPR shift. The LSPR shifting for NPs and fNPs in presence of RSV is compared with the LSPR of NPs (see Additional file 1). There was shifting of LSPR with all RSV titer for the functionalized copper nanoparticles at 30,60 and $120 \mathrm{~min}$ (Fig. 5). Increasing the time of contact between nanoparticles and RSV (all dose) did not have significant difference, except at $30 \mathrm{~min}$ time point for 2000 PFU RSV. The non-functionalized copper nanoparticles did not show significant change in the shifting. 


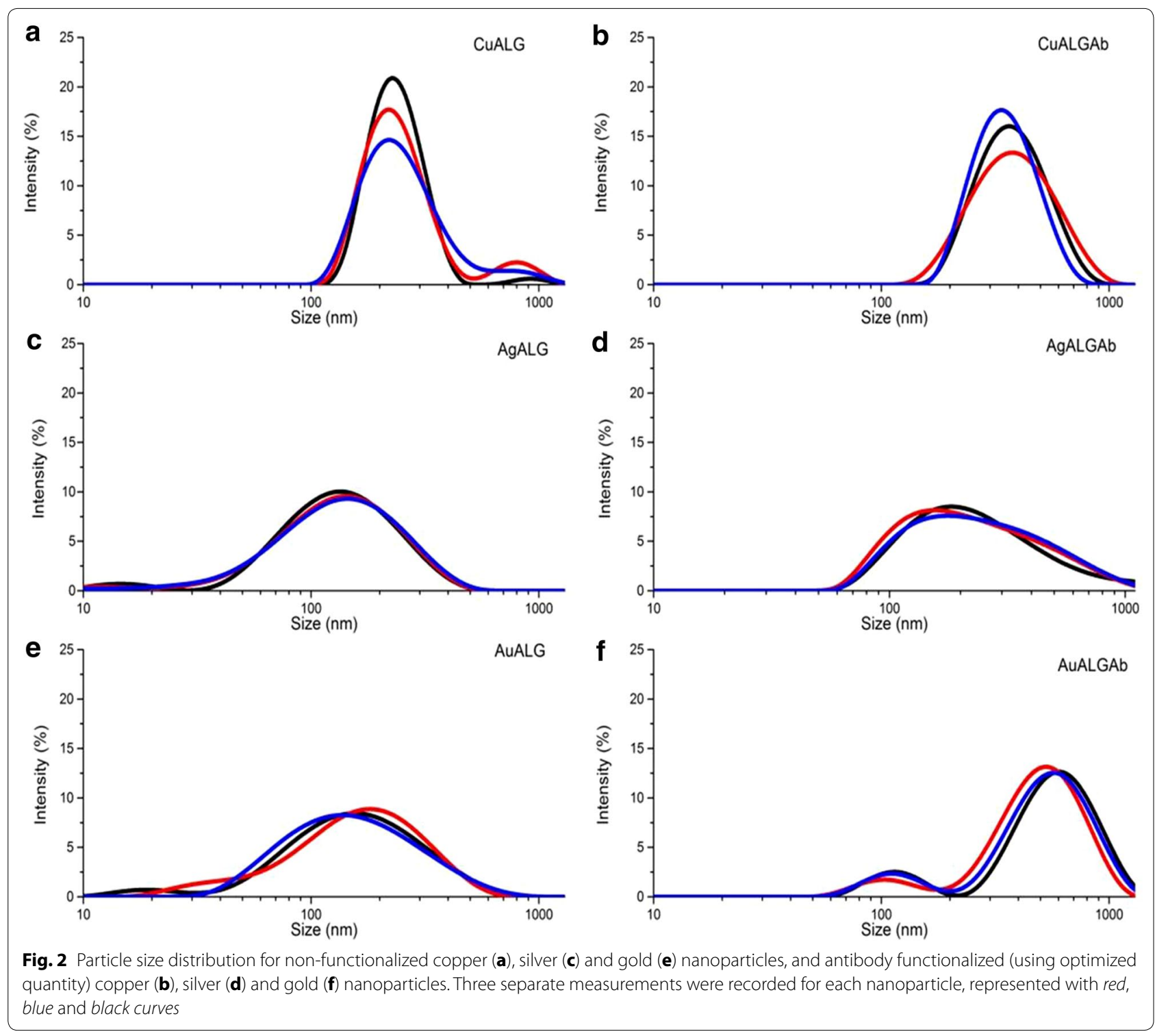

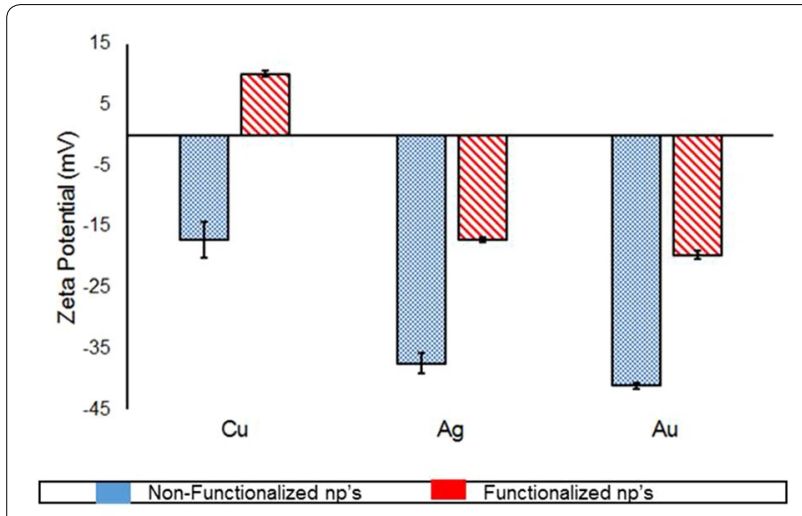

Fig. 3 Zeta potential for non-functionalized (b/ue) and antibody functionalized copper, silver and gold nanoparticles (red) dispensed in water at $\mathrm{pH}$ of 6.58 measured at room temperature
The functionalized silver nanoparticles did not show any significant LSPR shifting at 30 and $60 \mathrm{~min}$ time point, however at $120 \mathrm{~min}$, there was significant shifting at all RSV titers. The NP did not any shifting, except an outlier for 2000 PFU RSV at $30 \mathrm{~min}$ (Fig. 6).

The functionalized gold nanoparticles did not show any significant LSPR shifting for 500 PFU RSV at any time point and a marginal shift for 1000 PFU RSV at all time points. There was a significant shift observed at 2000 PFU RSV and did not change with the increasing contact time (Fig. 7). At all-time points, the non-functionalized gold nanoparticles exhibited blue shifting for $500 \mathrm{PFU}$ RSV; and also at 60 and $120 \mathrm{~min}$, there was such blue shift for 1000 PFU RSV.

Based on these time and dose dependent study for RSV detection using fNPs, Pearson's correlation was 

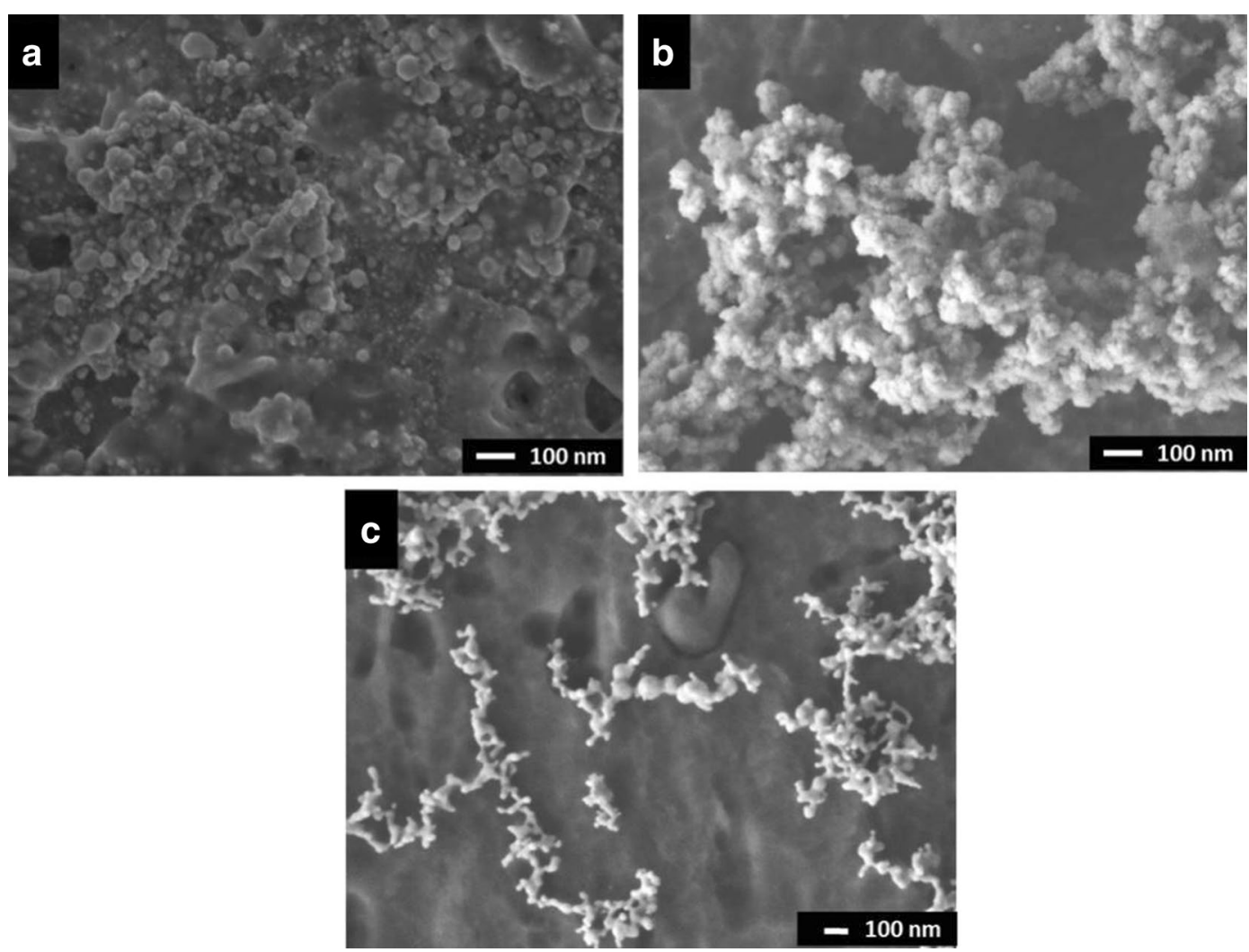

Fig. 4 Field-emission scanning electron micrographs of non-functionalized copper (a), silver (b) and gold (c) nanoparticles

calculated (Table 1) and limit of detection (LOD) and limit of quantification (LOQ) values were determined (Table 2). The best possible Pearson's co-efficient for functionalized copper and silver nanoparticles was 0.97 at $120 \mathrm{~min}$ and 0.87 at $60 \mathrm{~min}$, respectively. However, for gold it was in the range of $0.94-0.97$ at all-time points.

\section{Specificity and cross-reactivity}

Based best Pearson's linearity for the fNPs, the specificity and cross-reactivity were investigated in presence of $P$. aeruginosa and adenovirus. The functionalized copper nanoparticles $(120 \mathrm{~min})$, silver nanoparticles $(60 \mathrm{~min})$ and gold nanoparticles $(30 \mathrm{~min})$ were interacted with RSV and $P$. aeruginosa or adenovirus.

The non-functionalized and functionalized copper nanoparticle did not show any shift in presence of $P$. aeruginosa or RSV and P. aeruginosa together (Fig. 8a). However, there was no cross-reactivity for adenovirus and the fNPs specifically detected RSV in the presence of adenovirus (Fig. 9a). In case of silver nanoparticles, the fNP showed specificity for RSV in presence of $P$. aeruginosa (Fig. 8b) and adenovirus (Fig. 9b) by exhibiting significant LSPR shifting with no cross-reactivity. The non-functionalized and functionalized gold nanoparticles showed marginal shifting in for $P$ aeruginosa and adenovirus, suggesting cross-reactivity and lack of specificity towards RSV (Figs. 8c, 9c).

All the UV-visible analyses of the ANP and NP and their interaction with the RSV detection and specificity are summarized in the Fig. 10. The UV-visible spectra for these experiments are provided as Additional file 2 and Additional file 3 for P. aeruginosa and adenovirus, respectively.

\section{Discussion}

The biophysical methods for RSV detection are mainly PCR-ESI-MS and SERS, there is need for an alternative method to expand the ambit of RSV detection regime. The applications of metallic nanoparticles are extensive in the field of sensing and nanomaterial based sensors are widely used for development of cost-effective detection devices. SERS and LSPR are the popular sensing methods, which exploit the physicochemical peculiarity of particular metallic nanomaterials. The SERS utilizes metallic nanomaterial for detection of various analytes specifically even at extremely low levels, however, it is not cost-effective. The advantage of SERS can be offered by a simpler technique of LSPR spectroscopy [40]. LSPR 


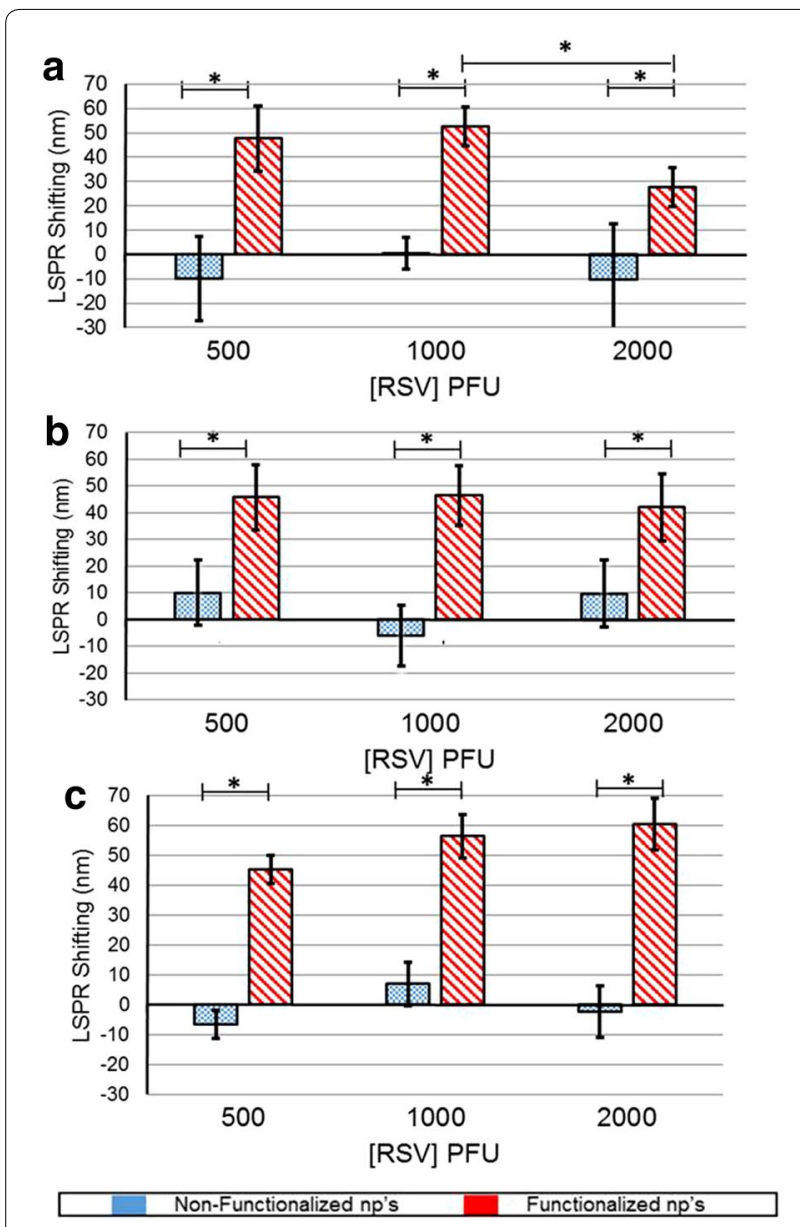

Fig. 5 Graph illustrates the LSPR shifting at different titres of RSV at $30 \mathrm{~min}(\mathbf{a}), 60 \mathrm{~min}(\mathbf{b})$ and $120 \mathrm{~min}$ (c) for antibody-functionalized (red) and non-functionalized (blue) copper nanoparticles. The asterisk symbol represents the significance $p<0.05$

based detection methods have been used for detection of hepatitis B virus [41], human immunodeficiency virus [26] and influenza virus [3, 42]. However, this study reports the LSPR based RSV detection using anti-RSV antibody functionalized metallic nanoparticles.

Generally, functionalization of the nanoparticle increases their size and consequently the width of the LSPR. Therefore, it is important to determine an optimal functionalization that provides scope for measurable LSPR (Fig. 1). The nature of nanoparticles and amount of functionalized biomolecules determine the LSPR, however the confounder may be non-specific interactions between nanoparticles may lead to agglomeration and affect the LSPR pattern (Fig. 1a) [43]. Our alginate reduced and stabilized copper, silver and gold nanoparticles size corroborate with the previous reports [44-46], as the specific plasmonic absorption relates to the nanometric size (Fig. 1). However, the particle size distribution indicates agglomeration of NP and fNP (Fig. 2) and as expected, the functionalization of nanoparticles reduced the zeta potential of the nanoparticles (Fig. 3). This may be the result of non-specific interactions (H-bonds, carboxyl groups, cross-linking) of alginate or antibody functionalization [47, 48]. We performed FE-SEM analyses to confirm the size of nanoparticles and it was found to be smaller than $100 \mathrm{~nm}$, however some agglomeration was evident (Fig. 4).

Time and titer dependent RSV detection with copper, silver and gold nanoparticles showed varied results. The interaction of RSV and antibody functionalized copper showed highest shifting as compared to silver and gold. The shifting was in the range of $45-60 \mathrm{~nm}$ at all time points (Fig. 5). At $120 \mathrm{~min}$, the functionalized copper nanoparticles showed highest linear correlation with the RSV titer (Table 1) with a LOD and LOQ of 2.4 and 14, respectively (Table 2 ). The functionalized silver nanoparticles did not interact prolifically with RSV as with the copper (Fig. 6). However, there was a shifting specific for RSV and at $60 \mathrm{~min}$, the LOD and LOQ values were calculated as 7 and 385 respectively (Tables 1,2). The gold nanoparticles functionalized with antibody resulted in shifting of LSPR in response to RSV binding. The shifting was more than silver nanoparticles; however, this system was better at higher RSV titer and more contact time (Fig. 7). Although, it has a convincing linearity, the LOD and LOQ values are 211 and 640, respectively (Tables 1, 2 ). The differences in these values of RSV shifting by copper, silver and gold nanoparticles (fNPs) can be due to the peculiar LSPR profile and the amount antibody functionalized on the nanoparticles.

For development of effective detection method, it is important to evaluate the cross-reactivity and specificity of the system. Therefore, we assessed fNP against respiratory pathogen $P$. aeruginosa and adenovirus for cross-reactivity and RSV specificity. We found that the fNP did not cross-react with the P. aeruginosa (Fig. 8) and adenovirus significantly (Fig. 9). However, the non-functionalized gold nanoparticles interacted marginally with $P$. aeruginosa and adenovirus as a result of non-specific interactions between the alginate coated nanoparticles and $P$. aeruginosa mucoid cell wall and adenovirus.

The specificity of our nanoparticles system to detect RSV in presence of $P$. aeruginosa and adenovirus is one of the highlights of the study. Functionalized copper and silver nanoparticles were able to specifically detect RSV even in the presence of $P$. aeruginosa and adenovirus, however the gold nanoparticles showed nonspecific shifting (Figs. 8, 9). It should be noted that the size of but $P$. aeruginosa is $(1.5-3.0 \mu \mathrm{m} \times 0.5-0.8 \mu \mathrm{m})$, almost 10 times bigger than RSV (150-300 nm). The titer of $P$. aeruginosa $\left(1-5 \times 10^{2} \mathrm{CFU}\right)$ and Adenovirus 


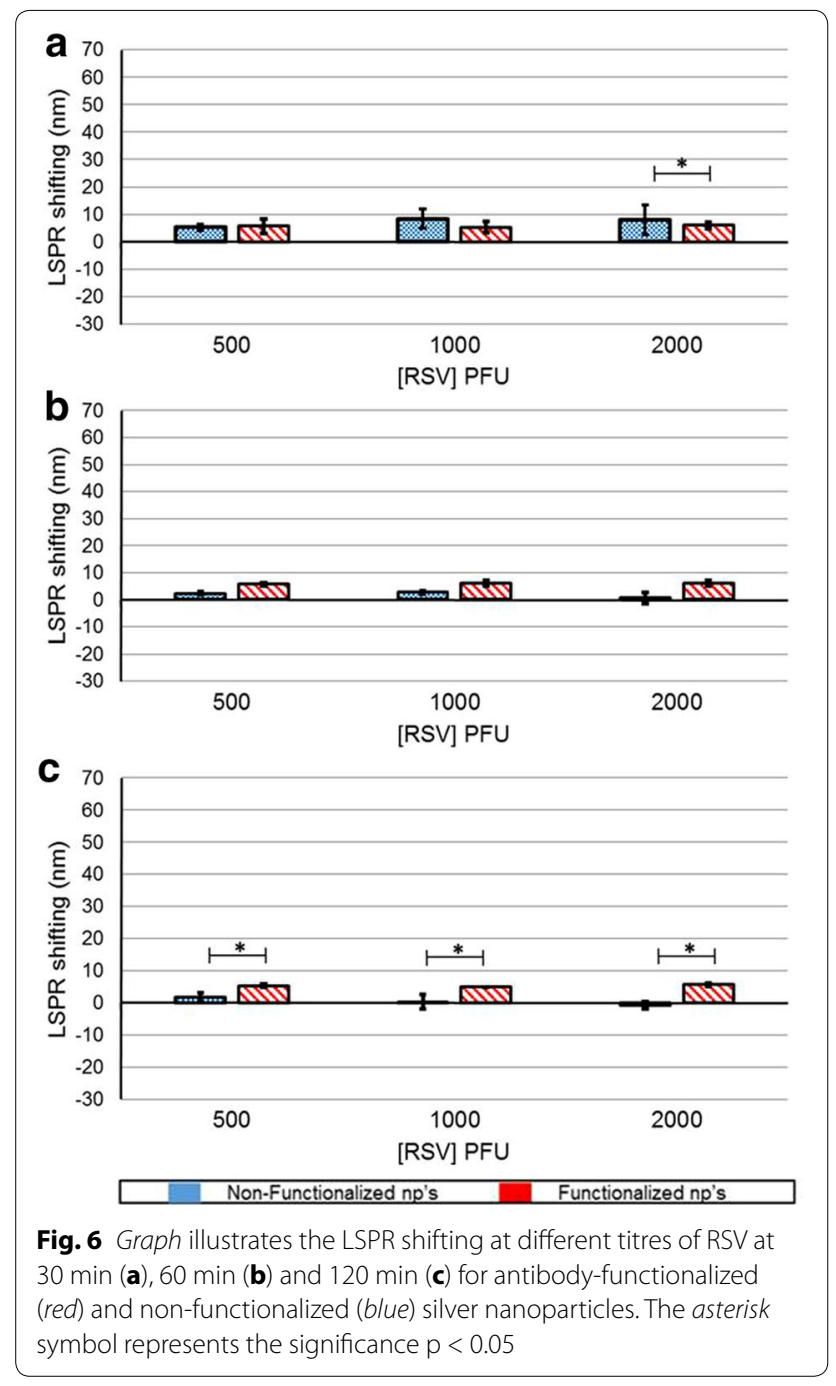

$\left(2.7 \times 10^{4}-11 \times 10^{4} \mathrm{PFU}\right)$ for the specificity experiments is considerably large. These factors adversely impact the LSPR shifting. However, we could still detect RSV and it shows the potential of LSPR detection system.

Overall, our study shows that metallic nanoparticles could be fabricated specifically for RSV detection; however, it is important to consider factors like suitable material, size, shape, contact time and LSPR behavior of nanoparticles for customized applications.

\section{Conclusions}

There is need for development of easy and rapid detection devices for respiratory pathogens like RSV, considering the fact that cost-effective and early detection of etiological agent results in effective treatment. Our results demonstrated the efficacy of antibody

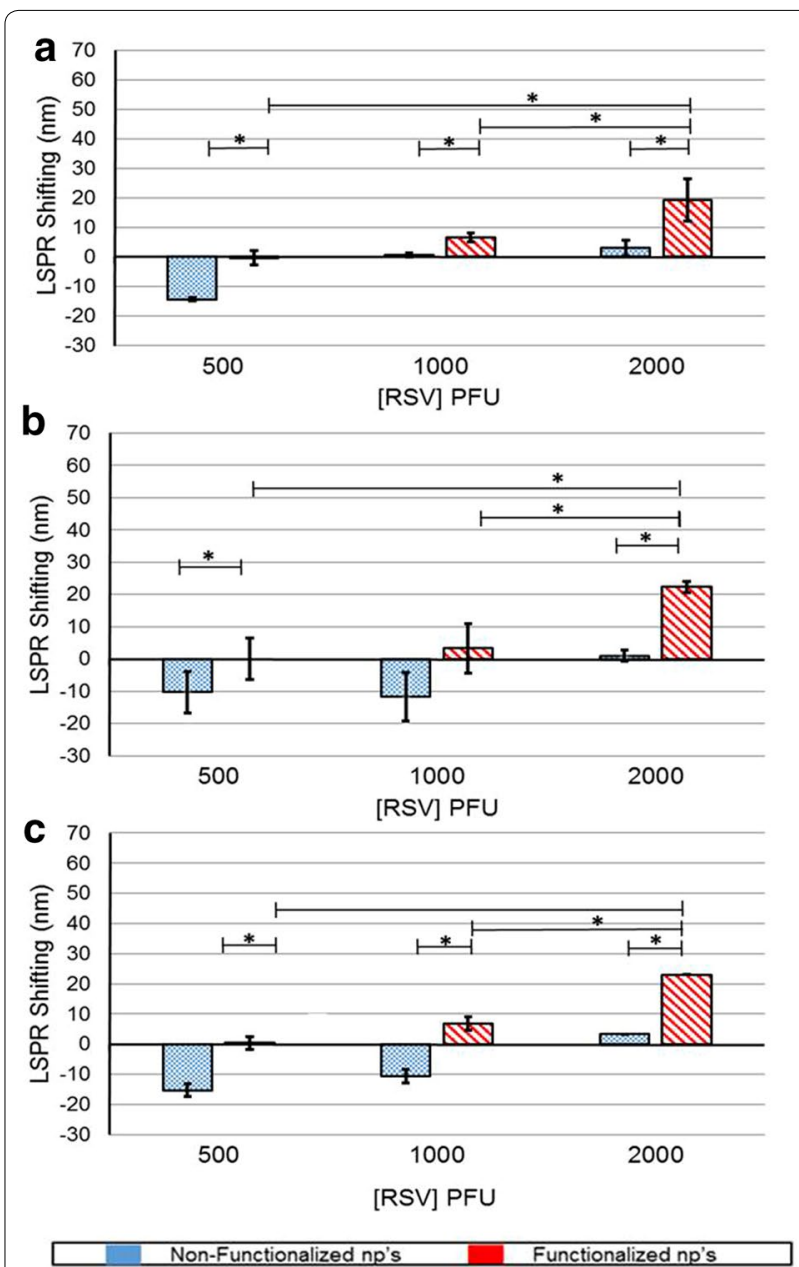

Fig. 7 Graph illustrates the LSPR shifting at different titers of RSV at $30 \mathrm{~min}(\mathbf{a}), 60 \mathrm{~min}(\mathbf{b})$ and $120 \mathrm{~min}$ (c) for antibody-functionalized (red) and non-functionalized (blue) gold nanoparticles. The asterisk symbol represents the significance $p<0.05$

Table 1 Pearson correlation coefficient for RSV titer (PFU) and time for antibody functionalized copper, silver and gold nanoparticles

\begin{tabular}{lcc}
\hline FNP & Time (min) & Pearson's R \\
\hline $\mathrm{Cu}$ & 30 & -0.76 \\
& 60 & -0.79 \\
& 120 & 0.97 \\
$\mathrm{Ag}$ & 30 & 0.50 \\
& 60 & 0.87 \\
& 120 & 0.50 \\
$\mathrm{Au}$ & 30 & 0.97 \\
& 60 & 0.94 \\
& 120 & 0.97 \\
\hline
\end{tabular}


Table 2 Limit of detection and limit of quantification values for RSV detection using antibody functionalized nanoparticles

\begin{tabular}{|c|c|c|c|}
\hline fNP & Time $(\min )$ & LOD (PFU) & LOQ (PFU) \\
\hline $\mathrm{Cu}$ & 120 & 2.4 & 14 \\
\hline $\mathrm{Ag}$ & 60 & 7 & 385 \\
\hline $\mathrm{Au}$ & 120 & 211 & 640 \\
\hline
\end{tabular}

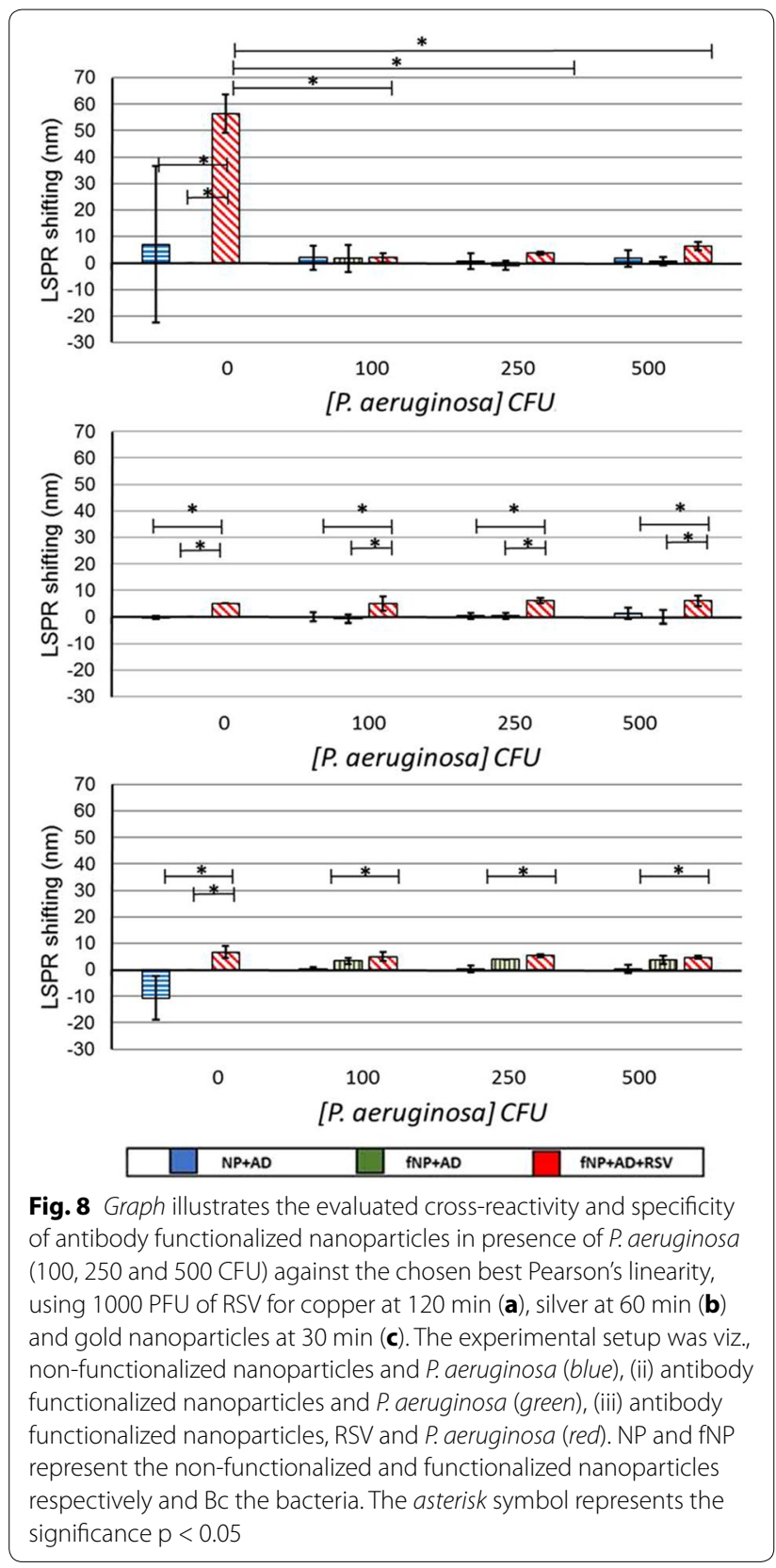

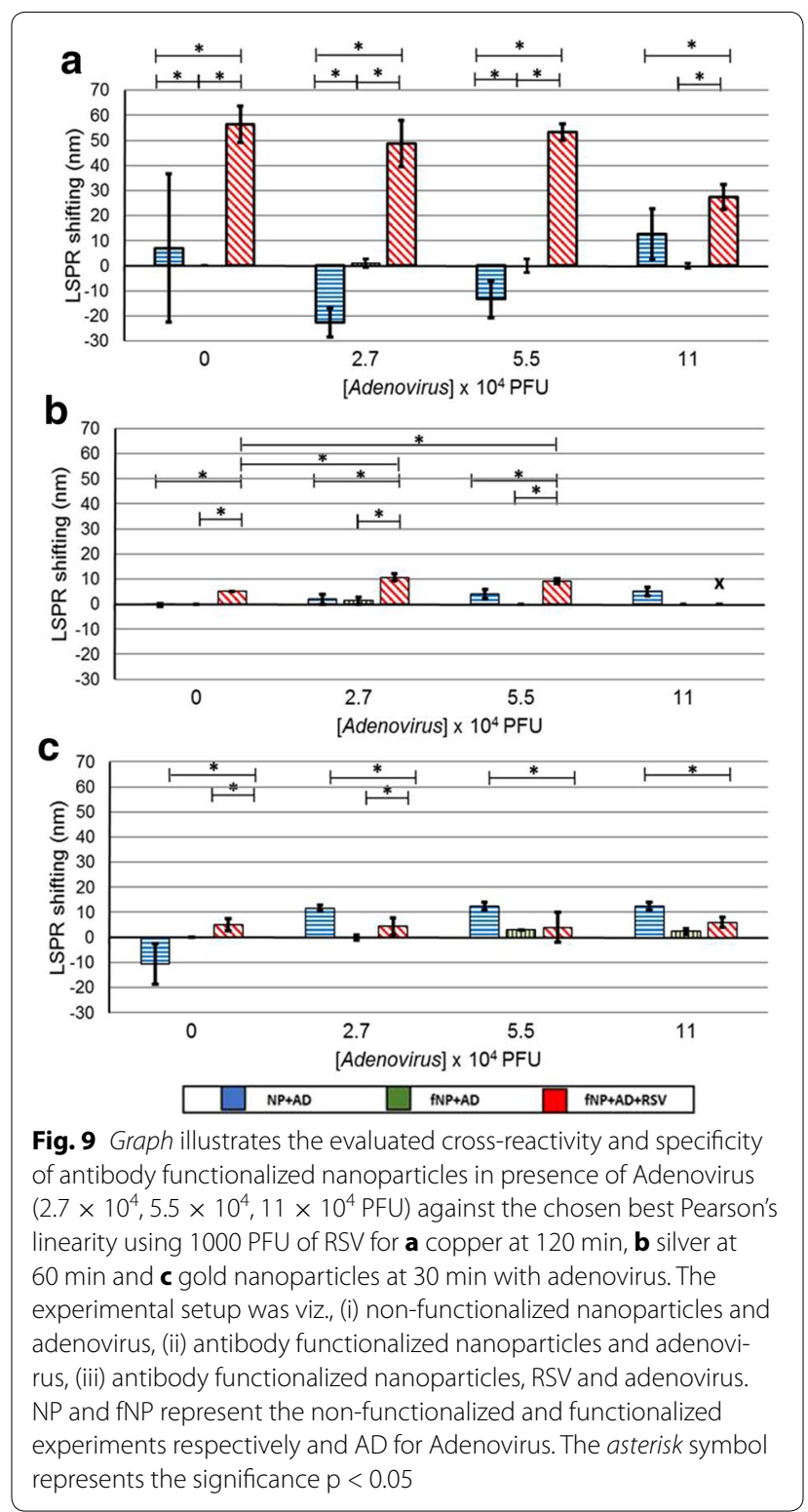

functionalized metallic (copper, silver and gold) nanoparticles for detected RSV using a simple and easy procedure of UV-visible spectroscopy. Detection of RSV in the presence of non-specific entities shows the potential of the LSPR based detection systems. Thus, LSPR is an easy and rapid alternative method for development of new detection devices for RSV.

\section{Methods}

\section{Synthesis of metallic nanoparticles}

The synthesis of metallic nanoparticles (NP) was carried out following a modified methodology from Kalwar 
1.- Synthesis of nanoparticles and antibody functionalization
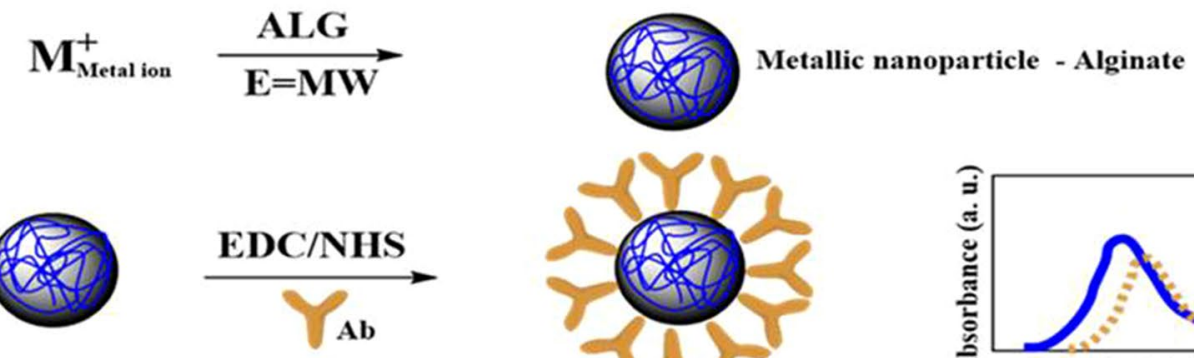

\section{2.- RSV detection}
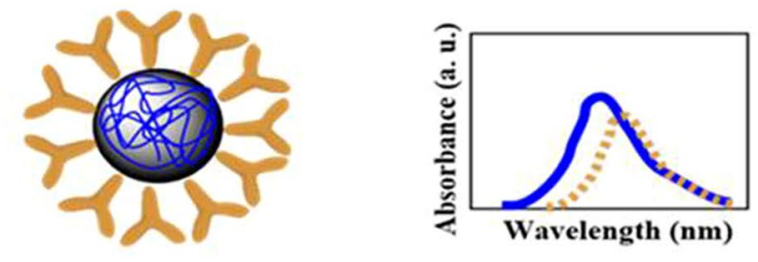

\section{Functionalized Np's}
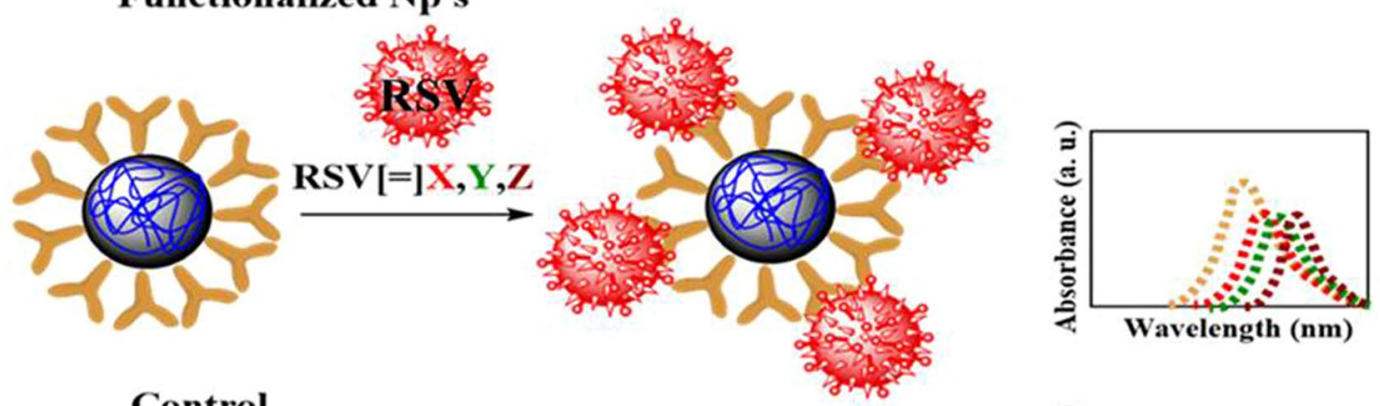

Control
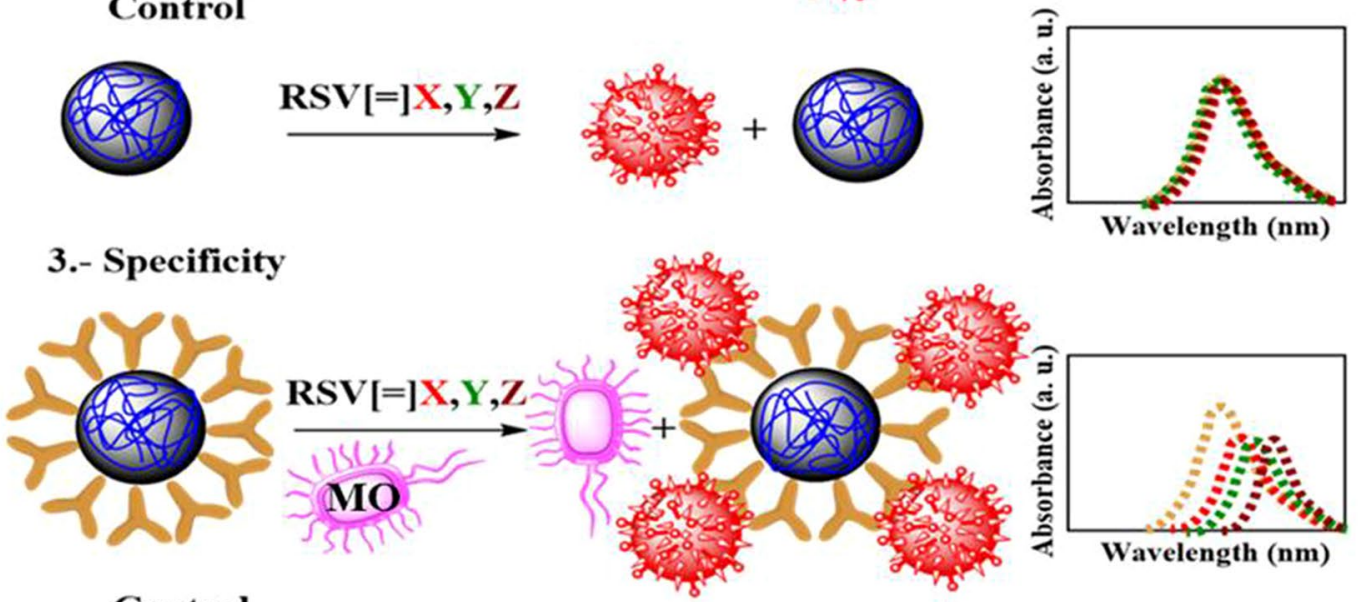

\section{Control}
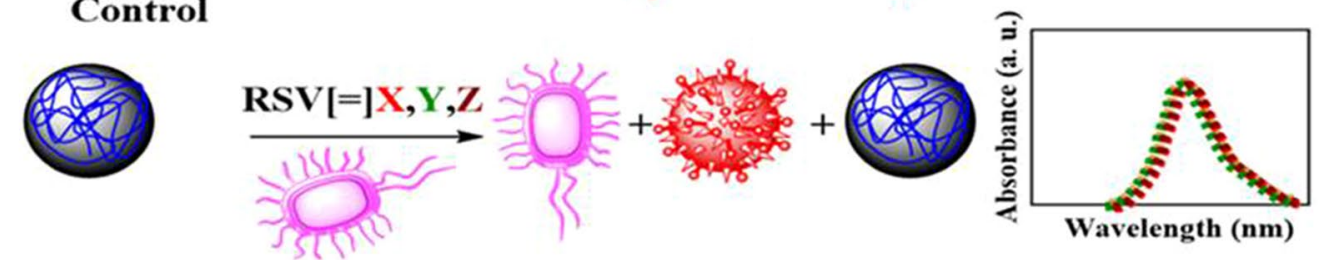

Fig. 10 Schematic overview of current study showing the LSPR behaviour of metallic nanoparticles upon surface modification with antibody. The interactions of functionalized nanoparticles with RSV and under the influence of microbial organism (MO: Pseudomonas aeruginosa and adenovirus) related to the shifting of UV-Vis spectra

et al. [49]. Briefly, in a beaker, $9 \mathrm{~mL}$ of ethylene glycol, $0.6 \mathrm{~mL}$ of sodium alginate $(10 \mathrm{mM})$ and $0.3 \mathrm{~mL}$ of $\mathrm{NaCO}_{3}$ were added $(0.1 \mathrm{M})$, mixed and the $\mathrm{pH}$ was adjusted at 11,10 and 12.5 for copper, silver and gold nanoparticles synthesis, respectively. To this, $1 \mathrm{~mL}$ of $10 \mathrm{mM}$ of $\mathrm{CuSO}_{4} \cdot 5 \mathrm{H}_{2} \mathrm{O}, 1.8 \mathrm{mg}$ of $\mathrm{AgNO}_{3}$ and $1 \mathrm{~mL}$ of $\mathrm{HAuCl}_{4}$ was added to respective beakers for copper, silver and gold nanoparticles synthesis. Then, the beakers were placed 
in the microwave (MW) for 3, 1 and 1 min for copper, silver and gold, which results the solutions to change the color to reddish, grey and purple for each system, respectively. At that point, the solutions were centrifuged at $10,000 \mathrm{rpm}$ for $30 \mathrm{~min}$ for copper and silver and for gold NPs were centrifuged at $8000 \mathrm{rpm}$ for $30 \mathrm{~min}$. The nanoparticles were then washed with distilled water 3 times using the same corresponding centrifuge conditions as mentioned above. Pelleted nanoparticles were suspended in distilled water (for copper and gold $0.5 \mathrm{~mL}$ water and $2 \mathrm{~mL}$ for silver).

\section{Functionalization of nanoparticles with antibody}

The functionalization was done using 1-Ethyl-3-(3dimethylaminopropyl) carbodiimide (EDC) chemistry. Filter sterilized $200 \mu \mathrm{L}$ of EDC $(1 \mathrm{mg} / \mathrm{ml}), 200 \mu \mathrm{L}$ of nanoparticles $(16.9 \pm 0.39,15.7 \pm 0.17$ and $8.3 \pm 0.3 \mathrm{mg})$ were placed in microcentrifuge tubes, and then $2.5,5$ and $10 \mu \mathrm{L}$ of polyclonal antibody $(4 \mathrm{mg} / \mathrm{mL})$ was added. The different amount of antibody was used to optimize the LSPR for each nanoparticle system. The solution was vortexed for $10 \mathrm{~s}$ and then placed on a titer plate shaker at room temperature for $3 \mathrm{~h}$. Microcentrifuge tubes were centrifuged at $8000 \mathrm{rpm}$ for $30 \mathrm{~min}$ and the supernatant was removed and stored (to be used for protein estimation). This process was repeated two more times and the pellet (nanoparticles) was re-suspended in $200 \mu \mathrm{L}$ of distilled water.

Non-functionalized (NP) and functionalized nanoparticles (fNP) were sonication for $10 \mathrm{~s}$ and analyzed by UV-visible spectroscopy (Beckman Coulter DU 800 Spectrophotometer), by taking $10 \mu \mathrm{L}$ of nanoparticles and making the volume to $50 \mu \mathrm{L}$ using distilled water.

\section{Particle size distribution and zeta potential}

The particle size distribution and zeta potential of nonfunctionalized and fNP were measured using a Zetasizer (Nano-ZS; Malvern Instruments Ltd, Malvern, UK). The nanoparticle solutions were diluted in distilled water, placing $50 \mu \mathrm{L}$ of the sample in $2 \mathrm{~mL}$ of distilled water $(\mathrm{pH}$ of $6.58 \pm 0.23$ ). The measurements for each sample were repeated three times.

\section{Determination of antibody functionalized on the nanoparticles}

The BCA protocol was used to quantify the antibody attached to the nanoparticles following manufacturer's instructions (Thermo Fisher Scientific, NY, USA). Briefly, $150 \mu \mathrm{L}$ of each standard (bovine serum albumin) and samples (washes from the fNPs) were placed into a microplate. Then, $150 \mu \mathrm{L}$ of the working reagent was added to each well and mixed thoroughly for $30 \mathrm{~s}$. The microplate was covered and incubated at $37{ }^{\circ} \mathrm{C}$ for $2 \mathrm{~h}$.
Then, the absorbance was measured at $562 \mathrm{~nm}$ on a plate reader.

\section{FE-SEM analysis}

For FE-SEM analysis, an aluminum substrate previously polished and washed with distilled water and acetone for three times was used. A drop of the nanoparticle's solution was placed on the substrate and it was allowed to evaporate at room temperature and imaged using JEOL JSM-7401f microscope (JEOL USA, Inc. MA, USA).

\section{RSV, Adenovirus and Pseudomonas aeruginosa}

Human respiratory syncytial virus (ATCC ${ }^{\circledR}$ VR-26 ${ }^{\mathrm{TM}}$ ), human adenovirus 5 ATCC $^{\circledR} \mathrm{VR}-5^{\mathrm{TM}}$ and $P$. aeruginosa (Schroeter) Migula (ATCC ${ }^{\circledR} 39324^{\mathrm{TM}}$ ) a mucoid strain were procured from American Type Culture Collection (ATCC) and maintained as instructed by ATCC. RSV and adenovirus were obtained in eagle's minimum essential medium supplemented with $2 \%$ FBS. While, $P$. aeruginosa was grown overnight in LB broth, pelleted, washed and suspended in sterile distilled water.

\section{LSPR based RSV detection}

The detection of RSV was performed using $10 \mu \mathrm{L}$ of LSPR optimized fNPs $(5 \mu \mathrm{L}$ of Ab for copper and gold and $10 \mu \mathrm{L}$ for silver) to which $2.5 \mu \mathrm{L}$ (500 PFU), $5 \mu \mathrm{L}$ (1000 PFU) and $10 \mu \mathrm{L}$ (2000 PFU) of RSV was added and incubated at room temperature on a shaker for 30, 60 and $120 \mathrm{~min}$. Distilled water was then adding to tubes to make up the volume of $60 \mu \mathrm{L}$ and analyzed using a UVvis spectrophotometer. Similarly, $10 \mu \mathrm{L}$ of NPs were also interacted with RSV as control.

\section{Evaluating the specificity and cross-reactivity of fNPs}

In order to assess the specificity of RSV detection for copper, silver and gold fNPs, the LSPR shifting was measured under the influence of $P$. aeruginosa and Adenovirus. The cross-reactivity of fNP was tested by observing the shifting upon P. aeruginosa and Adenovirus addition. Therefore, the experimental setup was (i) NPs $+P$. aeruginosa, (ii) $\mathrm{fNPs}+P$. aeruginosa, (iii) $\mathrm{fNPs}+\mathrm{RSV}+P$. aeruginosa. Similar experimental setup was designed for Adenovirus. The dose of $P$. aeruginosa used for this experiments was $1 \mu \mathrm{L}$ (100 CFU), $2.5 \mu \mathrm{L}$ (250 CFU) or $5 \mu \mathrm{L}(500 \mathrm{CFU})$; and $2.5 \mu \mathrm{L}\left(2.7 \times 10^{4} \mathrm{PFU}\right), 5 \mu \mathrm{L}$ $\left(5.5 \times 10^{4} \mathrm{PFU}\right)$ or $10 \mu \mathrm{L}\left(1.1 \times 10^{5} \mathrm{PFU}\right)$ of the Adenovirus. Based on the best linearity (Pearson's R) of the corresponding nanoparticles (fNPs) the time and titer (RSV) were selected.

The LSPR was measure using UV-visible spectroscopy as described earlier in the RSV detection section. Briefly, in a microcentrifuge tube, $10 \mu \mathrm{L}$ of the NPs/fNPs and $P$. aeruginosa were allowed to interact and also in the other 
tube, fNPs were allowed to incubate with RSV and P. aeruginosa together. Finally, the volume was increased to $60 \mu \mathrm{L}$ and absorbance was measured. In the same manner, specificity and cross-reactivity of fNPs in presence of adenovirus was evaluated.

\section{Statistical analysis}

All the experiments were performed in triplicates and the results were analyzed using OriginLab ${ }^{\mathrm{TM}} 9$ software and presented as mean \pm standard deviation. Results were subjected to two-way ANOVA, and a Tukey test was applied for RSV detection and specificity experiments. The differences were significant at $\mathrm{p}<0.05{ }^{(*)}$.

The limit of detection and quantification were calculated for the experiments at different times which had the best linearity (120 min for copper, $60 \mathrm{~min}$ for silver and $30 \mathrm{~min}$ for gold) using the following equation [50]:

(1) $\mathrm{LOD}=3.3\left(\sigma_{(\mathrm{x}, \mathrm{y})} / \mathrm{slope}\right)$

(2) $\mathrm{LOQ}=10\left(\sigma_{(\mathrm{x}, \mathrm{y})} / \mathrm{slope}\right)$

\section{Additional files}

Additional file 1. UV-vis spectra for the RSV detection.

Additional file 2. UV-vis spectra for the specificity and cross-reactivity experiments for $P$. aeruginosa.

Additional file 3. UV-vis spectra for the specificity and cross-reactivity experiments for adenovirus.

\section{Abbreviations}

[RSV]: RSV titer; RSV: respiratory syncytial virus; Ab: antibody; BCA: bicinchoninic acid; CFU: colony forming units; DFA: direct florescent antibody; DNA: deoxyribonucleic acid; EDC: 1-Ethyl-3-(3-dimethylaminopropyl) carbodiimide; ELISA: enzyme-linked immunosorbent Assay; HIV: human immunodeficiency virus; LOD: limit of detection; LOQ: limit of quantification; LSPR: localized superficial plasmon resonance; MW: microwave; fNP: functionalized nanoparticles; NP: non-functionalized nanoparticle; PCR: polymerase chain reaction; PFU: plaque forming units; QD: quantum dots; SERS: surface-enhanced Raman spectroscopy; FESEM: field-emission scanning electron microscopy; UV-vis: ultraviolet-visible.

\section{Authors' contributions}

JV conducted the experimental analysis. JV and SB designed, acquired and analyzed the data for the experiments and they wrote the manuscript. IG and SS participated in the analysis of the data and they helped to edit the manuscript for the critical revision. All authors read and approved the final manuscript.

\section{Authors' information}

$\mathrm{JV}$ is Master of Science in Materials Chemistry at Universidad Autónoma de Nuevo León. His study involves synthesis of metallic nanoparticles for biosensing applications.SB is a Ph.D candidate (Microbiology) at the Center for NanoBiotechnology Research, Alabama State University. He earned his Master (Biotechnology) from R.T.M. Nagpur University, India. His research interest involves nanoparticles mediated antiviral gene response and development of polymeric nanoparticles.

IG earned her Ph D in Materials Engineering and is a full time Professor at Universidad Autónoma de Nuevo León. Her research involves the synthesis of nanoparticles, graphene and QD's for biological, catalysis and energy applications.
SS earned his Ph.D from Auburn University, USA and is currently the Director of the Center for NanoBiotechnology Research and Professor of Microbiology at Alabama State University. He is an expert in area of nanovaccines and therapeutics for RSV and Chlamydia.

\section{Author details}

${ }^{1}$ Laboratorio de Materiales I, Facultad de Ciencias Químicas, Centro de Laboratorios Especializados, Universidad Autónoma de Nuevo León, Av. Pedro de Alba, 66451 Monterrey, Nuevo León, Mexico. ${ }^{2}$ Center for NanoBiotechnology Research, Alabama State University, 1627, Harris way, Montgomery, AL 36104, USA.

\section{Acknowledgements}

Part of this research was supported by National Science Foundation- CREST (HRD-1241701), NSF-HBCU-UP (HRD-1135863) and National Institutes of Health-MBRS-RISE (1R25GM106995-01) grants. The authors are also grateful for financial support from Mexico's National Council of Science and Technology (Consejo Nacional de Ciencia y Tecnología).

\section{Competing interests}

The authors declare that they have no competing interests.

Received: 3 November 2015 Accepted: 17 February 2016

Published online: 27 February 2016

\section{References}

1. Ehud Gazit AM. Plenty of room for biology at the bottom: an introduction to bionanotechnology. 2nd ed. 2013

2. Sanders M, Lin Y, Wei J, Bono T, Lindquist RG. An enhanced LSPR fiberoptic nanoprobe for ultrasensitive detection of protein biomarkers. Biosens Bioelectron. 2014;61:95-101. doi:10.1016/j.bios.2014.05.009.

3. Park TJ, Lee SJ, Kim DK, Heo NS, Park JY, Lee SY. Development of label-free optical diagnosis for sensitive detection of influenza virus with genetically engineered fusion protein. Talanta. 2012;89:246-52. doi:10.1016/j. talanta.2011.12.021.

4. Jiang S, Win KY, Liu S, Teng CP, Zheng Y, Han M-Y. Surface-functionalized nanoparticles for biosensing and imaging-guided therapeutics. Nanoscale. 2013;5(8):3127-48. doi:10.1039/C3NR34005H.

5. Voisin V, Pilate J, Damman P, Megret P, Caucheteur C. Highly sensitive detection of molecular interactions with plasmonic optical fiber grating sensors. Biosens Bioelectron. 2014;51:249-54. doi:10.1016/j. bios.2013.07.030.

6. Bazak R, Houri M, El Achy S, Kamel S, Refaat T. Cancer active targeting by nanoparticles: a comprehensive review of literature. J Cancer Res Clin Oncol. 2015;141(5):769-84. doi:10.1007/s00432-014-1767-3.

7. Lee K, Lee H, Bae KH, ParkTG. Heparin immobilized gold nanoparticles for targeted detection and apoptotic death of metastatic cancer cells. Biomaterials. 2010;31(25):6530-6. doi:10.1016/j.biomaterials.2010.04.046.

8. Wang CF, Makila EM, Kaasalainen MH, Hagstrom MV, Salonen JJ, Hirvonen JT, et al. Dual-drug delivery by porous silicon nanoparticles for improved cellular uptake, sustained release, and combination therapy. Acta Biomater. 2015;16:206-14. doi:10.1016/j.actbio.2015.01.021.

9. Lajunen T, Viitala L, Kontturi LS, Laaksonen T, Liang H, Vuorimaa-Laukkanen $\mathrm{E}$, et al. Light induced cytosolic drug delivery from liposomes with gold nanoparticles. J control Release: Off J Control Release Soc. 2015;203:85-98. doi:10.1016/j.jconrel.2015.02.028.

10. Haes AJ, Chang L, Klein WL, Van Duyne RP. Detection of a biomarker for Alzheimer's disease from synthetic and clinical samples using a nanoscale optical biosensor. J Am Chem Soc. 2005;127(7):2264-71. doi:10.1021/ ja044087q.

11. Saleh M, Soliman H, El-Matbouli M. Gold nanoparticles as a potential tool for diagnosis of fish diseases. Methods Mol Biol. 2015;1247:245-52. doi:10.1007/978-1-4939-2004-4_19.

12. Hess O, Pendry JB, Maier SA, Oulton RF, Hamm JM, Tsakmakidis KL. Active nanoplasmonic metamaterials. Nat Mater. 2012;11(7):573-84 doi:10.1038/nmat3356. 
13. Khan MS, Chaudhari VR. Morphological effect on fluorescence behavior of silver nanoparticles. J Fluoresc. 2014;24(3):751-7. doi:10.1007/ s10895-014-1348-5.

14. Zhang T, Song YJ, Zhang XY, Wu JY. Synthesis of silver nanostructures by multistep methods. Sensors. 2014;14(4):5860-89. doi:10.3390/ s140405860.

15. Amendola V, Bakr O, Stellacci F. A study of the surface plasmon resonance of silver nanoparticles by the discrete dipole approximation method: effect of shape, size, structure, and assembly. Plasmonics. 2010;5(1):85-97. doi:10.1007/s11468-009-9120-4.

16. Stewart ME, Anderton CR, Thompson LB, Maria J, Gray SK, Rogers JA, et al. Nanostructured plasmonic sensors. Chem Rev. 2008;108(2):494-521. doi:10.1021/cr068126n.

17. Moirangthem RS, Yaseen MT, Wei P-K, Cheng J-Y, Chang Y-C. Enhanced localized plasmonic detections using partially-embedded gold nanoparticles and ellipsometric measurements. Biomed Opt Express. 2012;3(5):899-910. doi:10.1364/BOE.3.000899.

18. Song HD, Choi I, Lee S, Yang YI, Kang T, Yi J. On-chip colorimetric detection of Cu2 + ions via density-controlled plasmonic core-satellites nanoassembly. Anal Chem. 2013;85(16):7980-6. doi:10.1021/ac401796q.

19. Nagatsuka T, Uzawa H, Sato K, Kondo S, Izumi M, Yokoyama K, et al. Localized surface plasmon resonance detection of biological toxins using cell surface oligosaccharides on glyco chips. ACS Appl Mater Interfaces. 2013;5(10):4173-80. doi:10.1021/am4002937.

20. Avasthi DK, Mishra YK, Singhal R, Kabiraj D, Mohapatra S, Mohanta B, et al. Synthesis of plasmonic nanocomposites for diverse applications. J Nanosci Nanotechnol. 2010;10(4):2705-12.

21. Fong KE, Yung LY. Localized surface plasmon resonance: a unique property of plasmonic nanoparticles for nucleic acid detection. Nanoscale. 2013;5(24):12043-71. doi:10.1039/c3nr02257a.

22. Zhao J, Das A, Schatz GC, Sligar SG, Van Duyne RP. Resonance localized surface plasmon spectroscopy: sensing substrate and inhibitor binding to cytochrome P450. J Phys Chem C. 2008;112(34):13084-8. doi:10.1021/ jp801719c.

23. Lan T, Dong C, Huang $X$, Ren J. A sensitive, universal and homogeneous method for determination of biomarkers in biofluids by resonance light scattering correlation spectroscopy (RLSCS). Talanta. 2013;116:501-7. doi:10.1016/j.talanta.2013.07.024.

24. Guo L, Kim D-H. LSPR biomolecular assay with high sensitivity induced by aptamer-antigen-antibody sandwich complex. Biosens Bioelectron. 2012;31(1):567-70. doi:10.1016/j.bios.2011.10.047.

25. Barlen B, Mazumdar S, Lezrich O, Kämpfer P, Keusgen M. Detection of Salmonella by surface plasmon resonance. Sensors. 2007;7(8):1427.

26. Lee J-H, Kim B-C, Oh B-K, Choi J-W. Highly sensitive localized surface plasmon resonance immunosensor for label-free detection of HIV-1. Nanomed Nanotechnol Biol Med. 2013;9(7):1018-26. doi:10.1016/j. nano.2013.03.005.

27. Vidic J. Surface plasmon resonance immunosensor for detection of pb1-f2 Influenza A Virus protein in infected biological samples. J Anal Bioanal Tech. 2013;. doi:10.4172/2155-9872.s7-006

\section{(citeulike-article-id:13659056)}

28. Shanmukh S, Jones L, Zhao YP, Driskell JD, Tripp RA, Dluhy RA. Identification and classification of respiratory syncytial virus (RSV) strains by surface-enhanced Raman spectroscopy and multivariate statistical techniques. [1618-2650 (Electronic)].

29. Tripp RA, Alvarez R, Anderson B, Jones L, Weeks C, Chen W. Bioconjugated nanoparticle detection of respiratory syncytial virus infection. Int J Nanomed. 2007;2(1):117-24.

30. Chattopadhyay PK, Price DA, Harper TF, Betts MR, Yu J, Gostick E et al. Quantum dot semiconductor nanocrystals for immunophenotyping by polychromatic flow cytometry. Nat Med. 2006;12(8):972-7. http://www. nature.com/nm/journal/v12/n8/suppinfo/nm1371_S1.html.

31. Krilov LR. Respiratory syncytial virus disease: update on treatment and prevention. Expert Rev Anti Infect Ther. 2011;9(1):27-32. doi:10.1586/ eri.10.140.
32. Thompson WW, Shay DK, Weintraub E, Brammer L, Cox N, Anderson LJ, et al. Mortality associated with influenza and respiratory syncytial virus in the United States. JAMA. 2003;289(2):179-86.

33. Diaz PV, Calhoun WJ, Hinton KL, Avendano LF, Gaggero A, Simon V, Arredondo SM et al. Differential effects of respiratory syncytial virus and adenovirus on mononuclear cell cytokine responses. [1073-449X (Print)].

34. de Vrankrijker AM, Wolfs Tf, Ciofu O, Hoiby N, van der Ent CK, Poulsen SS, Johansen HK et al. Respiratory syncytial virus infection facilitates acute colonization of Pseudomonas aeruginosa in mice. [1096-9071 (Electronic)].

35. Bawage SS, Tiwari PM, Pillai S, Dennis V, Singh SR. Recent advances in diagnosis, prevention, and treatment of human respiratory syncytial virus. Adv Virol. 2013;2013:26. doi:10.1155/2013/595768.

36. Sampath R, Russell KL, Massire C, Eshoo MW, Harpin V, Blyn LB, et al. Global surveillance of emerging influenza virus genotypes by mass spectrometry. PLoS One. 2007;2(5):e489. doi:10.1371/journal.pone.0000489.

37. Chen K-F, Blyn L, Rothman RE, Ramachandran P, Valsamakis A, Ecker $D$, et al. RT-PCR and electrospray ionization mass spectrometry (RT$\mathrm{PCR} / \mathrm{ESI}-\mathrm{MS}$ ) for identifying acute viral upper respiratory tract infections. Diagn Microbiol Infect Dis. 2011;69(2):179-86. doi:10.1016/j. diagmicrobio.2010.10.010.

38. Demirel MC, Kao P, Malvadkar N, Wang H, Gong X, Poss M, et al. Bio-organism sensing via surface enhanced Raman spectroscopy on controlled metal/polymer nanostructured substrates. Biointerphases. 2009;4(2):35-41. doi:10.1116/1.3147962.

39. Hudson SD, Chumanov G. Bioanalytical applications of SERS (surfaceenhanced Raman spectroscopy). Anal Bioanal Chem. 2009;394(3):679-86. doi:10.1007/s00216-009-2756-2.

40. Willets KA, Van Duyne RP. Localized Surface Plasmon Resonance Spectroscopy and Sensing. Annu Rev Phys Chem. 2007;58(1):267-97. doi:10.1146/ annurev.physchem.58.032806.104607.

41. Wang X, Li Y, Wang H, Fu Q, Peng J, Wang Y, et al. Gold nanorod-based localized surface plasmon resonance biosensor for sensitive detection of hepatitis B virus in buffer, blood serum and plasma. Biosens Bioelectron. 2010;26(2):404-10. doi:10.1016/j.bios.2010.07.121.

42. Hong Y, Huh Y-M, Yoon DS, Yang J. Nanobiosensors based on localized surface plasmon resonance for biomarker detection. J Nanomater. 2012;2012:13. doi:10.1155/2012/759830.

43. Anker JN, Hall WP, Lyandres O, Shah NC, Zhao J, Van Duyne RP. Biosensing with plasmonic nanosensors. Nat Mater. 2008;7(6):442-53.

44. Amendola V, Meneghetti M. Size evaluation of gold nanoparticles by uv-vis spectroscopy. J Phys Chem C. 2009;113(11):4277-85. doi:10.1021/ jp8082425.

45. Bhui DK, Bar H, Sarkar P, Sahoo GP, De SP, Misra A. Synthesis and UV-vis spectroscopic study of silver nanoparticles in aqueous SDS solution. J Mol Liq. 2009;145(1):33-7. doi:10.1016/j.molliq.2008.11.014.

46. Khatoon UT, Nageswara Rao GVS, Mohan MK, editors. Synthesis and characterization of copper nanoparticles by chemical reduction method. Advanced Nanomaterials and Emerging Engineering Technologies (ICANMEET), 2013 International Conference on;2013: 24-26. July 2013.

47. King AH. Brown seaweed extracts (alginates). In Food hydrocolloids. Florida: CRC Press; 1983.

48. Dobson PJ. Biosensors and molecular technologies for cancer diagnostics, edited by Keith E. Herold and Avraham Rasooly. Contemporary Physics. 2013;54(1):76-7. doi:10.1080/00107514.2013.766641.

49. Kalwar N, et al. Microwave-assisted synthesis of L-cysteine-capped nickel nanoparticles for catalytic reduction of 4-nitrophenol. Rare Met. 2015. doi:10.1007/s12598-015-0475-8.

50. Shrivastava A, Gupta V. Methods for the determination of limit of detection and limit of quantitation of the analytical methods. Chronicles Young Sci. 2011;2(1):21-5. doi:10.4103/2229-5186.79345. 